\title{
CONSTRUÇAO DE BIBLIOTECA ESPECTRAL DE SOLO DA BAHIA
}

\author{
Estefane Santana Oliveira ${ }^{1}$ e Rodrigo Vasconcelos ${ }^{2}$ \\ ${ }^{1}$ Bolsista PIBIC/CNPq, Graduando em Geografia, Universidade Estadual de Feira de Santana, e-mail: \\ estefanesantanaoliveira@gmail.com \\ ${ }^{2}$ Orientador, Departamento de Ciências Exatas, Universidade Estadual de Feira de Santana, e-mail: \\ nvuefsppgm@gmail.com
}

PALAVRAS-CHAVE: Biblioteca Espectral; Solos; Sensoriamento Remoto.

\section{INTRODUÇÃO}

O solo é um corpo natural, tridimensional que pode apresentar caraterísticas do material de origem e é um recurso natural importantíssimo para a sobrevivência dos seres humanos, pois é a partir dele que extraímos alimentos, alicerçamos e edificamos nossas casas é sobre o solo que vimemos. Para Lepsch (2010, p.19) o solo é uma coleção de corpos naturais dinâmicos, contendo matéria viva que resulta da ação do clima e dos organismos atuando sobre um material de origem.

O sensoriamento remoto (SR) é uma ciência que permite, estudar e levantar informações de objeto ou área de estudo sem toca-los a partir de sensores. Souza (2010) aborda o SR enquanto ciência e arte na obtenção das informações sobre um objeto, área ou fenômeno, de modo que essa arte requer a interação da radiação eletromagnética e do objeto. A caraterística dos solos atualmente tem sido descrita a partir do uso de técnicas de SR, em função da possibilidade extração de informações no tempo e espaço, por meio de modelos que descrevem o comportamento espectral e a composição dos alvos em questão. O SR permite uma análise detalhada a respeito de algumas caraterísticas dos solos como tipo, matéria orgânica, textura, presença de minerais e unidade do solo, granulometria e química do solo. Com a disponibilização destes dados é possível fazer a descriminação das classes de solo, para organizar criar um banco de dados, a Biblioteca Espectral (BE)

Nesse sentido, a BE é a coleção de dados de amostras de solos da Bahia, que conta com classificação de tipos de solos, local de ocorrência (coordenada geográfica) e arquivo espectral (curva espectral e arquivo txt.). O banco de dados possibilitará a utilização de uma maior densidade amostral, e praticidade, onde busca-se os dados regionais concentrados em escala com maior riqueza de detalhes, visto que a aplicação do uso do espectrorradiometria tem custo baixo e rápida precisão. 


\section{MATERIAL E MÉTODOS OU METODOLOGIA (ou equivalente)}

No desenvolvimento da pesquisa científica seguiram os seguintes procedimentos metodológicos: Levantamento bibliográfico; Identificação das amostras de solos do Labespectro; Processamento dos dados das amostras sendo construída uma biblioteca espectral específica para cada grupo de amostras de solos, e depois estes dados foram catalogados e organizados em tabela do Excel; Elaboração mapas para especializar as amostras de solo do laboratório; Elaboração de gráficos contendo as curvas espectrais das amostras; Analise de dados das amostras a partir de curvas espectrais, utilizando as bandas de absorção para identificar a mineralogia e gerar os arquivos AscII do tipo txt, que compõe o banco de dados, Organização dos dados das amostras de solo em planilhas; Construção da BE.

\section{RESULTADOS E/OU DISCUSSÃO (ou Análise e discussão dos resultados)}

As bibliotecas espectrais contribuíram na evolução e no aprimoramento do SR, as mesmas funcionam como uma espécie de catalogo digital de solo. Assim, ela "é um conjunto de informações espectrais e analíticas que podem ser consultadas e estudadas para fins ambientais e pedológicos" (Sato, 2015, p.36). A BE de solos da Bahia buscas organizar e disponibilizar para a comunidade a acadêmica os dados dos solos coletado pelo laboratório de espectrorradiometria do programa de modelagem e ciências da terra e do ambiente.

Para Belinasso, (2009) o uso do SR contribui para a identificação dos solos e de seus atributos, porém ainda é uma técnica pouco aplicada, a forma de torna esta técnica mais proficiente é estabelecer padrões abrangentes e detalhados que esteja disponível para o público. Sua criação serve como base nos estudos do solo a partir dos padrões característicos apresentados por cada curva espectral de referência, na identificação e discriminação de classes dos alvos em estudo, além da praticidade e viabilidade na realização das análises do solo.

No desenvolvimento de uma BE é necessário considerar o número das amostras, buscando representar variedade espacial de solos encontrados, na Bahia as amostras incialmente presentes no laboratório de espectrorradiometria Labespectro, são de 16 municípios, sendo estes localizados na faixa Norte do Estado e no município de feira de Santana na faixa Leste, com 150 amostras de solo que foram trabalhadas, podendo ser observado no Mapa 1. 
No processo inicial, catalogação, organização e espacialização dos dados foram gerados mapas dos locais com dados de solo catalogados pelo Labespectro. Os seguintes solos foram catalogados: Argissolo, Cambissolo, Chernossolo, Latossolo, Luvissolo, Neossolo, Planossolo e Vertissolo.

Em todos estes solos é perceptível a presença de óxidos de ferro, na forma côncava da curva. Por isto é comum a presença de goethita e/ou hematita, a predominância de um ou outro este associado aos processos pedogenéticos. Estes minerais têm influência marcante nas características do solo, como na coloração e estão presentes na maioria dos solos intemperizados de clima tropical e subtropical. Os locais de baixa temperatura e maior presença de água, favorece a formação da goethita. Os locais com temperaturas mais quentes e menos úmidos favorecem a formação da hematita. (OLIVEIRA, 2017). A goethita e a hemática influenciam as variações espectrais, assim como a caulinita, minerais $1: 1$ e a montmorilonita 2:1. A caulinita é frequente encontrada nos solos tropicais, a sua curva espectral possui características facilmente identificáveis. A montmorilonita, é um argilomineral expansivo, por isto possui maior quantidade de água e a sua identificação na curva de um solo é percebida pela absorção de $\mathrm{H} 2 \mathrm{O}$.

Para estruturar a BE foi construído um catálogo com os dados dos solos que compõem o acervo do laboratório como características, físicas biologias e químicas, a classificação segundo a EMBRAPA e os minerais identificados, com esta planilha será possível montar a biblioteca, tornando fácil a identificação das classes de solo através das curvas espectrais e dos demais atributos presentes na planilha. Os arquivos com os dados referentes a biblioteca também estão organizados, de acordo como na figura 1 e 2 , para facilitar o acesso e torna a obtenção de informação mais rápida, desta forma é possível acessar estes dados através do link: https://drive.google.com/open?id=183TH0MW8CaUU4_dMZRmhh-8WDUk0r8pu. Em cada pasta com o nome de solo, tem outras pastas com o nome das cidades onde as amostras foram colhidas, nestas, encontra-se a curva espectral de cada amostra, identificada pelo seu código e a analise da curva em formato JPG. Também é possível acessar a planilha com dados das amostras de solo através do link: https://drive.google.com/open?id=1ZHe0Asht73PrXfHwAhR1zD0wKig5Q Z1.

\section{CONCLUSÃO}

A construção da BE se constitui enquanto uma alternativa para levantamentos 
pedológicos mais rápidos, pois as atuais formas ainda consomem muito tempo, são onerosos e necessitam de grande número de análises laboratoriais. Com a BE passa-se a ter maior eficiência na predição de atributos de solos de maneira rápida e menos poluente. Para a caracterização de classes de solo, quanto para a estimativa de atributos é necessário o desenvolvimento de Bibliotecas Espectrais, que contenham dados representativos da variabilidade dos solos

É possível concluir que a montagem da BE contribuiu para avanços nas técnicas qualitativas e quantitativas de avaliação espectral dos solos, sendo possível caracterizar distintas classes de solos e utilizar essas informações para classificar perfis de classe desconhecida a partir de dados espectrais.

Durante a pesquisa os dados evidenciaram que cada solo apresenta uma linha individual e característica, permitindo concluir quanto a viabilidade na construção da biblioteca espectral bem como as contribuições dos estudos pedológicos na Bahia, gerando inovações das informações e compartilhamento das mesmas, demostrando assim o potencial da ciência do sensoriamento remoto e da técnica de espectrorradiometria nos estudos do solo.

\section{REFERENCIAS}

BELINASSO, Henrique. Biblioteca espectral de solos e sua aplicação na quantificação de atributos e classificação. Dissertação de mestrado. Piracicaba 2009. BEN-DOR, E.; IRONS, J.R.; EPEMA, G.F. Soil reflectance. In: RENCZ, A.N. Remote sensing for the earth sciences. John Wiley:, New York, 1998. p.111-188.

OLIVEIRA, Marceli Terra de. Comportamento espectral de antropossolos decapíticos revegetados com adição de lodo de esgoto. Brasília. UNB, 2017.

SISTEMA brasileiro de classificação de solos. 3. ed. rev. e ampl. Rio de Janeiro: Empresa Brasileira de Pesquisa Agropecuária - Embrapa Solos; Brasília, DF: Embrapa Informação Tecnológica, 2013

SATO, Marcos Vinícios. Primeira aproximação da biblioteca espectral de solos do brasil: caracterização de espectros de solos e equação de atributos. Piracicaba, 2015. 102p dissertação de mestrado.

SOUZA; Ronald Buss de. Sensoriamento Remoto: conceitos fundamentais e plataformas. Centro Regional Sul de Pesquisas Espaciais - CRS Instituto Nacional de Pesquisas Espaciais - INPE. Santa Maria- RS.2010.Disponível em: http://www.inpe.br/crs/crectealc/pdf/ronald_ceos.pdf> acessado em 19-03-17 as 17:50. 